\title{
Reading the first early Cenozoic central Arctic sediment record: A palynological view
}

Francesca Sangiorgi ${ }^{1,2}$, A. Sluijs ${ }^{1}$, J. Barke ${ }^{1}$ and H. Brinkhuis ${ }^{1}$

'Laboratory of Palaeobotany and Palynology, Institute of Environmental Biology, Utrecht University, Netherlands; f.sangiorgi@uu.nl

2 Department of Marine Biogeochemistry and Toxicology, Royal Netherlands Institute for Sea Research, Texel, Netherlands

Palynological analyses performed on long sedimentary records from the crest of the Lomonosov Ridge (Arctic Ocean) indicates that the Arctic developed from a warmer-than-expected, semi-isolated, shallow, freshwater dominated, eutrophic basin during the early Paleogene, to a sea-ice and iceberg dominated ocean during most of the Neogene. During the Eocene, the environmental changes were orbitally paced, with a biological response strongly affected by obliquity.

The Cenozoic history of the Arctic Ocean was largely unknown from direct evidence prior to Integrated Ocean Drilling Program (IODP) Expedition 302 (or ACEX, the Arctic Coring EXpedition) in 2004, when sediments were drilled on the crest of the Lomonosov Ridge (LR), in water depths of $1300 \mathrm{~m}, 250 \mathrm{~km}$ from the North Pole (Fig. 1).

The spliced stratigraphic section of $430 \mathrm{~m}$ (Fig. 1) includes an Upper Cretaceous basement, underlying sediments that were deposited on the LR after its rifting from the Eurasian continental margin $\sim 58 \mathrm{Ma}$ (Glebovsky et al., 2006). An unexpected hiatus from $\sim 44-\sim 18$ Ma separates the Paleogene "Greenhouse" from the Neogene "Icehouse" sections (Moran et al., 2006; Backman et al., 2008; Sangiorgi et al., 2008a). Four years of intensive, multidisciplinary research has resulted in a basic understanding of the Arctic environment, oceanography and climate. The picture obtained, however, represents only snapshots of the Lomonosov Ridge during its migration from the Eurasian continent to its present location, and suggests a basin geographically different from today's during most of the early Cenozoic (Fig. 1). The Arctic developed from a warmer-than-expected, semi-isolated, shallow, freshwater dominated, eutrophic basin during much of the early Palaeogene (e.g., Brinkhuis et al., 2006; Sluijs et al., 2006; Pagani et al., 2006), to a sea-ice and iceberg dominated ocean during most of the Neogene (Moran et al., 2006; Darby et al., 2008; Krylov et al., 2008). Along with providing the most continuous biostratigraphical tool (Backman et al., 2008, Fig. 1), palynology (the study of organic-walled dinoflagellate cysts (dinocysts), pollen, spores and other organic remains) has been pivotal for unraveling the history of the Arctic basin across several intervals of the Cenozoic.

\section{Paleocene-Eocene Greenhouse and "hyperthermals"}

Dinocyst assemblages throughout the latest Paleocene and early Eocene, including the PETM (Paleocene/Eocene Thermal

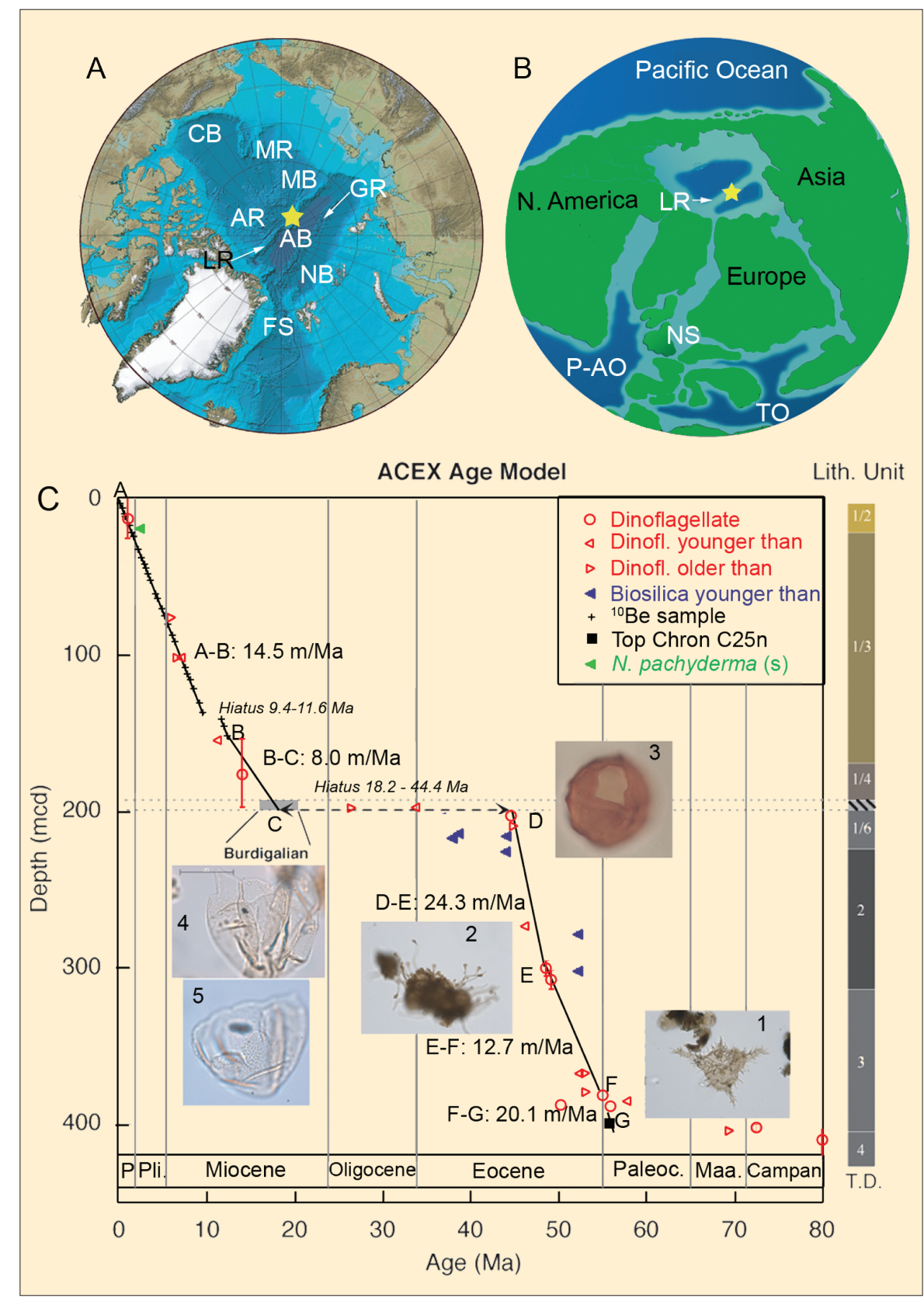

Figure 1: A) Arctic Ocean map (modified from International Bathymetric Chart of the Arctic Ocean, Jakobsson et al., 2000), with indication of the Arctic sub-basins and ridges: AR, Alpha Ridge; FS, Fram Strait; GR, Gakkel Ridge; LR, Lomonosov Ridge; MR, Mendeleev Ridge; MB, Makarov Basin; NB, Nansen Basin; AB, Amundsen Basin; CA, Canada Basin. Star indicates the location of IODP 302 drilling on the LR; B) Location of drilling within the early Eocene paleogeographical reconstruction of the Arctic Ocean (Brinkhuis et al., 2006) TO, Tethyan Ocean; P-AO, Proto-Atlantic Ocean; NS, North Sea; C) ACEX age model (modified from Backman et al., 2008) with indication of the Lithologic Units (Lith. Unit) and sub-units (Expedition 302 Scientists, 2006). Pictures of the dinoflagellate cysts Apectodinium augustum (1), Phthanoperidinium clithridium (3), Arcticacysta backmanii (4), A. moraniae (5) and the remains of Azolla (2) used as biostratigraphical markers are also shown. The palynological events considered in building the age model in the early Cenozoic are: Last Occurrence (LO) of A. augustum (F), LO of Azolla (E), Last Abundant Occurrence of P. clithridium (D) and the mid point of the Burdigalian stage where A. backmanii and A. moraniae occur (C). The oldest identified paleomagnetic chron datum (top of magnetochron C25n, Chron (25n), (G) deepest Berillium-10 samples (B) and top of the section (A) on which the age model is based are also shown. TD: Terminal Depth. Depth scale in meters composite depth (mcd). 


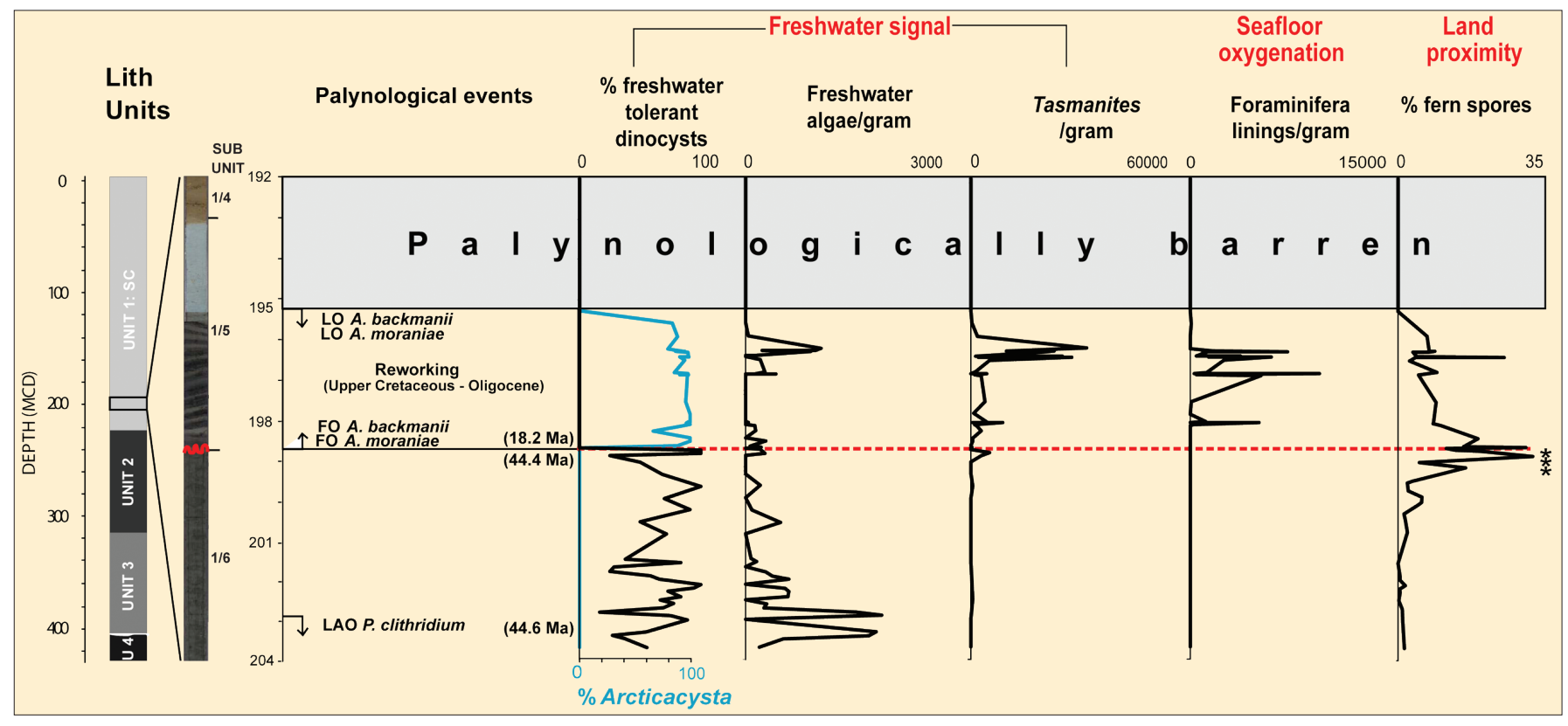

Figure 2: $\boldsymbol{A}$ ) Lithostratigraphic column showing the lithologic units and sub-units recognized in the ACEX section (Expedition 302 Scientists, 2006); $\boldsymbol{B}$ ) image of the core section showing the hiatus (wiggly red line); $\boldsymbol{C}$ ) Dinocyst events used to identify the location and duration of the hiatus, see text for full species names, $L O=$ last occurrence, LAO = last abundant occurrence, $F O=$ First Occurrence; $\boldsymbol{D})$ Selected palynological proxies and their environmental interpretation, hiatus = red dashed line, Asterisks = abundant occurrence of fungal spores (see text). Depth scale in meters composite depth (mcd).

Maximum, $\sim 55 \mathrm{Ma}$ ), point to brackish and productive Arctic surface waters (Sluijs et al., 2008). The influx of Apectodinium spp., which prior to the PETM were characteristic of (sub)tropical regions, suggests a significant warming during the PETM (Sluijs et al., 2006). Consistent with this interpretation is an organic biomarkerbased concomitant sea surface and air warming from an initial temperature value of 18 to $23^{\circ} \mathrm{C}$ (Sluijs et al., 2006; Weijers et al., 2007). Sea level rose, while anoxic and euxinic (i.e., anerobic, waters with restricted circulation) conditions developed in the bottom waters and photic zone, respectively (Sluijs et al., 2006), favored by increased moisture delivery to the Arctic and a strong hydrological cycle and, consequently, an enhanced geological weathering cycle (Pagani et al., 2006; Schouten et al., 2007; Sluijs et al., 2008). Such high temperatures imply unexpectedly small poleequator temperature gradients, far from the expectations based on paleoclimate models (e.g., Huber and Nof, 2006), and require feedback mechanisms other and/ or stronger than those already included in the simulations (Sluijs et al., 2006). Approx. $20 \mathrm{~m}$ above the PETM section, the Eocene Thermal Maximum 2 ( 53.5 Ma) was identified in the core (Stein et al., 2006; Sluijs et al., 2008) and is currently subject to intensive dinocyst and geochemical analyses.

\section{The Arctic "lake" phase: The Azolla event}

Large quantities of remains of the freefloating freshwater fern Azolla were found in the LR core at the onset of the middle Eocene ( 49 Ma). Abundant Azolla remains are characteristic of middle Eocene marine deposits of all Nordic seas (e.g., Bujak and Mudge, 1994). Since Azolla concentrations in the LR core were found to be one order of magnitude higher than elsewhere, the Arctic was likely the source of Azolla transported to the Nordic seas. Azolla and accompanying abundant freshwater organic microfossils indicate episodic, cyclic, orbitally (likely obliquity) driven freshening of Arctic surface waters during an $\sim \mathrm{Ma}$ interval, (Brinkhuis et al., 2006; Speelman et al., in press). The Azolla phase is accompanied by an increase of $\sim 3 \%$ in the total organic carbon from background levels. This increased carbon burial may have influenced the global carbon cycle (Speelman et al., in press), as the termination of the Azolla phase coincides with the beginning of the long-term Cenozoic cooling (e.g., Zachos et al., 2008). The cause(s) for the termination of the Azolla phase are still largely unknown. The Azolla demise coincides with a local sea surface temperature rise from $10^{\circ} \mathrm{C}$ during the Azolla phase to $13^{\circ} \mathrm{C}$ at its demise, pointing to simultaneous increases in salt and heat supply owing to the influx of waters from adjacent oceans (Brinkhuis et al., 2006). On-going (paleo-)ecological, botanical, physiological and geochemical studies, together with growing experiments on the living relative(s) of the fossil Azolla, are being performed at Utrecht and Nijmegen Universities (The Netherlands), in collaboration with international partners, to better constrain the Azolla event (duration, geographical distribution, effect on the carbon cycle, etc.) in the Eocene Arctic. These will shed light on the climatic and oceanographic importance of the Arctic Ocean during warm greenhouse conditions and its implication for global climate. More information on the on-going "Azolla project" is available at www.bio.uu.nl/ palaeo/ Azolla/Azolla.htm

\section{The first sea ice in the mid- Eocene and orbital modulation of environmental changes}

Middle Eocene ( 46 Ma) cores also contain evidence of ice-rafted debris, as indicated by grain texture and composition analyses of terrigenous sand (St. John, 2008). The same sediments have revealed strong cyclicity in the terrigenous sand accumulation, in several geochemical elements, and in biological proxies (dinocysts, pollen and spores, siliceous microfossils) (Sangiorgi et al., 2008b; Spofforth et al., 2008). Freshwater-tolerant dinocysts, pollen of flowering plants and chrysophyte cysts (freshwater siliceous microfossils) cyclically alternate with marine dinocysts, bisaccate pollen and marine diatoms, suggesting paced environmental changes. These results indicate that the biological response is strongly affected by obliquity (growing season length/darkness) at times of seaice formation in the Arctic, whereas the terrigenous components, directly driven by sea ice and/or glacial ice formation and extent, responded more directly to seasonal insolation (precession) (Sangiorgi et al., 2008b).

\section{Hiatus at the greenhouse- icehouse transition}

Biostratigraphical analyses, based mainly on dinocysts, have identified a $\sim 26 \mathrm{Ma}$ hiatus from the late middle Eocene ( 44.4 Ma) 
to the late early Miocene ( 18.2 Ma) (Figs. 1 and 2; Sangiorgi et al., 2008a; 2008c).

The hiatus is marked by a sharp change in sediment color, a few meters above the last abundant occurrence of the middle Eocene marker dinocyst species Phthanoperidinium clithridium. Sediments above the hiatus contain a new dinocyst genus, Arcticacysta, likely of Miocene (Burdigalian) age (Sangiorgi et al., 2008c). The two species found, Arcticacysta backmanii and $A$. moraniae, co-occur and dominate the interval, where sparse reworked dinocysts of Cretaceous to Oligocene age are also found (Fig. 2). Palynological analyses suggest that the hiatus marks the transition from an anoxic environment with a fresh-brackish water lid, to an estuary-like environment, where high freshwater in- put co-occurred with oxygenated bottom waters. When the sediments become palynologically barren (Fig. 2; Sangiorgi et al., 2008a), a fully ventilated oxic marine environment develops, likely as result of the opening and the deepening of the Fram Strait (Jakobsson et al., 2007). High abundance of fern and fungal spores in the sediments around the hiatus indicate that sediment deposition occurred either close to shore or on land, suggesting that unexpectedly, the Lomonosov Ridge remained at or near sea level for the duration of the gap, likely as a consequence of tectonic activity (O'Regan et al., 2008).

\section{Acknowledgements}

We thank the Netherlands Organisation for Scientific Research (NWO) for funding, and the In- tegrated Ocean Drilling Program for providing samples and data. Stefan Schouten, Jaap Sinninghe Damsté, ACEX co-chiefs Jan Backman and Kate Moran, and all the ACEX colleagues are thanked for the fruitful collaboration.

\section{References}

Backman J. et al., 2008: Age Model and Core-Seismic Integration for the Cenozoic ACEX Sediments from the Lomonosov Ridge, Paleoceanography, 23: PA1S03, doi:10.1029/2007PA001476

Brinkhuis, H. et al., 2006: Episodic fresh surface water in the Eocene Arctic Ocean, Nature, 441: 606-609.

Sangiorgi, F. et al., 2008a: A 26 million year gap in the central Arctic record at the Greenhouse-Icehouse transition: Looking for clues, Paleoceanography, 23: PA1504, doi:10.1029/2007PA001477

Sangiorgi, F. et al., 2008b: Cyclicity in the middle Eocene central Arctic Ocean sediment record: orbital forcing and environmental response, Paleoceanography, 23: PA1508, doi:10.1029/2007PA001487

Sluijs A. et al., 2006: Subtropical Arctic Ocean temperatures during the Paleocene/Eocene thermal maximum, Nature, 441: 610-613.

\title{
Potential imprint of changes in multidecadal climate variability on temperature reconstructions of the past millennium
}

\author{
Michael Schulz and Matthias Prange \\ MARUM - Center for Marine Environmental Sciences and Faculty of Geosciences, University of Bremen, Germany; mschulz@uni-bremen.de
}

\section{Model results suggest that the wider spread of individual Northern Hemisphere temperature reconstructions during cold phases of the last millennium may partly reflect enhanced climate variability at multidecadal timescales.}

A wide range of reconstruction techniques and proxy data have been used to infer how mean temperature of the Northern Hemisphere has changed over the past millennium (Jansen et al., 2007). This research is driven by the important question of whether the rate and amplitude of the warming during the past decades is unprecedented in the framework of the last millennium, that is, before humans affected the Earth System at an unparalleled magnitude.

The individual reconstructions (Jansen et al., 2007; Fig. 6.10 therein) agree with respect to the overall evolution of Northern Hemisphere temperature. This evolution comprises a warming towards the Medieval Warm Period (centered on the $11^{\text {th }}$ century $\left.A D\right)$, a subsequent cooling culminating in the Little Ice Age $\left(16^{\text {th }}\right.$ to mid- $19^{\text {th }}$ century $A D$ ), followed by the most recent warming. The reconstructed centennial-scale variability is thought to be mainly driven by changes in total solar irradiance and possibly also by volcanic eruptions (Jansen et al., 2007 and references therein). Upon closer visual inspection, the temperature reconstructions reveal that the widest spread between the reconstructions occurs before and after the Medieval Warm Period (Jansen et al., 2007; Fig. 6.10 therein). That is, the overlap between the individual reconstructions seems to be better for warm than for cold intervals.

Although each reconstruction is based on a proxy calibration in the recent warm

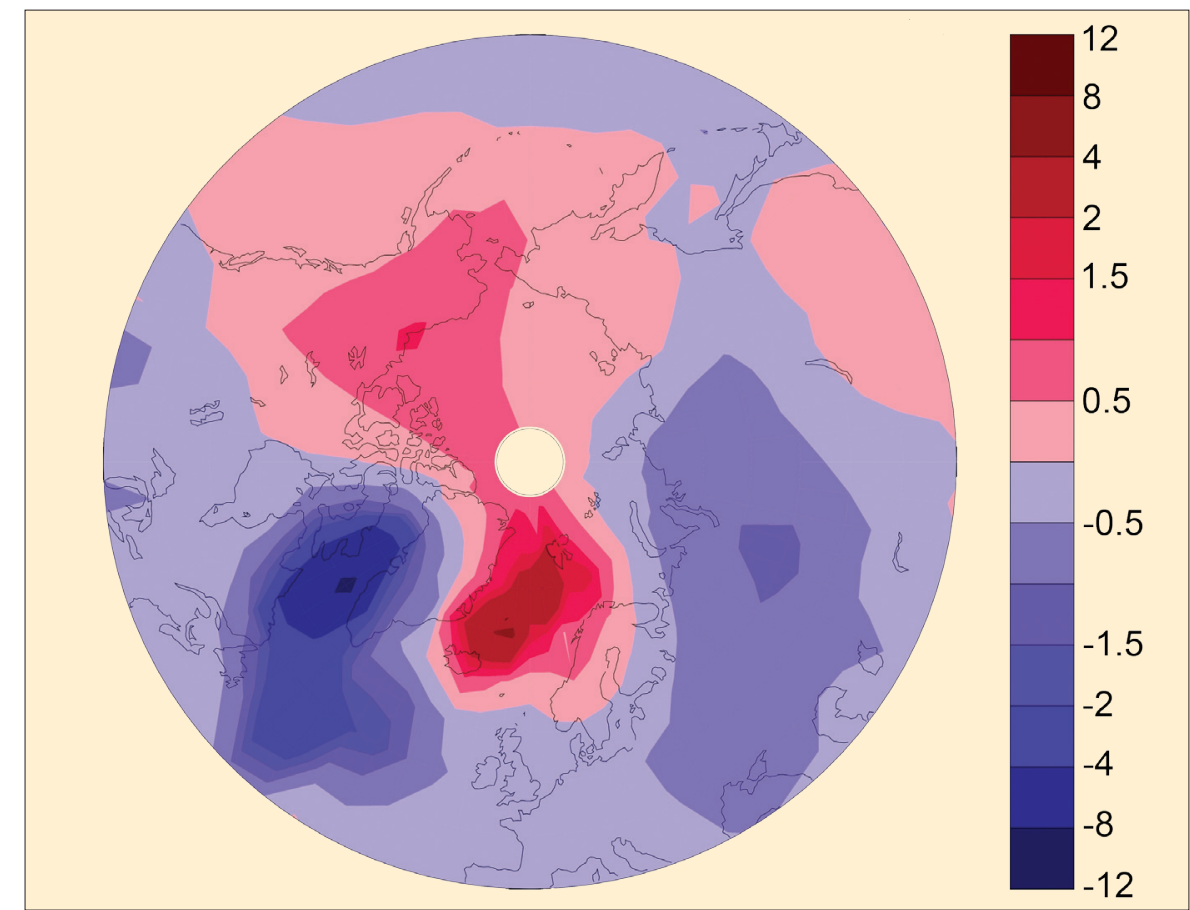

Figure 1: Surface air-temperature difference $\left({ }^{\circ} \mathrm{C}\right)$ between cold and warm mode in the Northern Hemisphere.

period, it appears that the divergence between the individual reconstructions cannot be entirely explained by such a calibration bias (cf., Mann et al., 2008). Another reason for the difference between the reconstructions could be changes in the density of the underlying proxy network, 